\title{
The Use of the Depository Catalog in a University Library ${ }^{1}$
}

$I^{n}$ $\mathrm{N}$ VIEW of the space consumed and the cost of upkeep which includes catalog cases and time spent in filing cards, a study of the frequency and types of use made of a depository catalog in a large university library is pertinent. Since the recently completed Catalog of Books Represented by Library of Congress Printed Cards Issued to July 31,1942 (referred to hereafter as Book Catalog) there has been much discussion as to the usefulness of the depository cards. Many librarians have decided that the limited use made of the depository catalog does not warrant the expense of maintenance and the space used, especially now that the Book Catalog is available, and the $\mathrm{Li}$ brary of Congress plans to issue current supplements. On the other hand, there are librarians who believe that the depository catalog should be maintained for various reasons, chief among which are (I) the cards are more easily read than the Book Catalog and (2) cards can be interfiled in order to keep the depository up-to-date and, therefore, the use of supplements which necessitates searching in more than one place is not necessary. The decision regarding the retention or disposal of the depository catalog is an administrative problem and should be based upon the results of carefully planned objective studies.

\section{Purpose of the Study}

This study was made for the purpose of isolating the uses that are made of the

1 Based on a master's essay prepared at the School of Library Service, Columbia University, 1946. depository catalog, noting the number of repetitive questions answered by its and testing the assumption that the depository catalog should be maintained. The depository catalog of the Columbia University Libraries was used as the medium for gathering data because of its accessibility and because there has been some question as to whether the frequency of use is enough to justify the space it occupies in the reference room of the main library. Although this is a case study, it was assumed that the findings would have some application to similar situations in other libraries.

The depository catalog consists of approximately two and one-half million cards housed in 2794 trays occupying about 540 square feet of wall space. It is located adjacent to the Columbia card catalog in the reference room of the Nicholas Murray Butler Library. Because of its size and continuous growth, the alphabet is divided into two parts. On the main floor are trays containing the alphabet from $\mathrm{A}$ to $\mathrm{M}$, and on the mezzanine floor directly above are trays containing the letters $\mathrm{N}$ to $\mathrm{Z}$. Also on the mezzanine floor, at the end of the alphabet, is filed the supplementary cata$\log .^{2}$ This supplement consists of Library of Congress cards printed after July I, 1942, and covers the entire alphabet. Since the Book Catalog includes cards issued to July 31,1942 , it was deemed advisable to file in a separate section the cards issued

2 After this study was made, the supplement wis transferred to the main floor and the catalog from $\mathrm{J}-\mathrm{Z}$ transferred to the mezzanine floor. 
after July I, 1942, including the revised cards.

The Columbia depository catalog is a union catalog in that some cards from the libraries of Harvard, the Vatican, John Crerar, Folger, and the Universities of Chicago and Michigan have been interfiled with the Library of Congress cards. It is not, however, as a union catalog that the depository set is to be considered in this study, although a few of the interfiled cards were used by persons interviewed.

The cost of maintaining the depository catalog is approximately $\$_{1} 600$ per year. Filing costs amount to $\$_{1} 400$, and card cases cost $\$ 200$.

Although a number of studies have been made of the different types of catalogs and their uses, the depository catalog as a problem to be studied has been neglected. Miller's study reports "what some patrons actually used among the various types of information given on the traditional and typical catalog card." ${ }^{3}$ Knapp ${ }^{4}$ and Swank ${ }^{5}$ discussed card catalogs chiefly from the subject point of view. Merritt, ${ }^{6}$ Stone,${ }^{7}$ and Berthold $^{8}$ have discussed union catalogs. A survey by $\mathrm{Nyholm}^{9}$ and an experiment conducted by Bryan, ${ }^{10}$ both of which pertain to the legibility of the Book Catalog, have

\footnotetext{
Miller, Robert A. "On the Use of the Card Catalog." Library Quarterly 12:630, April 1942.

"Knapp, Patricia B. "The Subject Catalog in the College Library." Library Quarterly 14:108-18, April 1944; $214-28$, July ro44. tions, or Bibliographies? A Review of Critical DisCussions, 1876

cMerritt, LeRoy Charles. "The Administrative, Fiscal and Quantitative Aspects of the Regional Union Catalog." (In Downs, Robert B., ed. Union Catalogs in the United States. Chicago, American Library Association, 1942, p. 3-1 25.)

'Stone, John Paul. "Regional Union Catalogs: A Study of Services Actual and Potential." (In Downs, Robert B., ed. Union Catalog in the United States. Chicago, American Library Association, 1942, p. 1292.25.)

Berthold, Arthur Benedict. "Manual of Union Catalog Administration." (In Downs, Robert B., ed. Union Catalogs in the United States. Chicago, American Library Association, 1942, p. 267-348.)

9 Nyholm, Jens. "Summary of Comments on a Cata$10 \mathrm{Nyholm}$, Jens. "Summary of Comments on a CataPrinted Cards, June 5, r943," Mimeographed.

Printed Bryan, Alice I. "Legibility of Library of Con. gress Cards and Their Reproductions." College and Research Libraries 6:447-64, September 1945, pt. 2.
}

a bearing upon the problem of the depository catalog.

Nyholm investigated and summarized comments made by librarians of twentythree selected libraries on the feasibility of replacing the depository catalog with the Book Catalog. Bryan made a study on the legibility of the Book Catalog as compared with the legibility of the printed cards. The consensus of those participating in both studies was that the print of the Book Catalog is uneven and has a tendency toward illegibility, especially in the L.C. card numbers.

A limited study was made by the writer in which every tenth page, beginning with page thirteen of volume thirty-one (Coles, Abraham-Comstock, Frederick Harmon) was sampled. None of the 1152 entries examined was found to be entirely illegible. It would seem that the amount of illegibility, while undesirable, is not enough to interfere greatly with the normal uses made of the Book Catalog.

\section{Collecting the Data}

A plan was devised whereby interviews with all users of the catalog would be conducted over a period of time sufficiently long enough to permit drawing valid conclusions concerning its use. An interview schedule patterned after the tally card and the check sheet offered by Miller and Stone in their studies was constructed and utilized.

In the formulation of the interview schedule for this study, the following points were considered: ( 1 ) examination of literature on the various catalogs, (2) the known uses of the depository catalog, (3) consultation with catalogers and other members of the staff. Two questions were kept in mind-(I) How frequently and by whom is the depository catalog consulted? and (2) What uses are made of the depository cata$\log$ ? Convenience in handling the schedule 
and ease in tabulating the replies were also considered. In order to secure the best results quickly, the schedule was cast in the form of a checklist or tally card which might be answered by placing a checkmark opposite the appropriate statements or by adding necessary notes to record the desired information. It was designed to answer the following questions: Which items on the depository cards are being searched for and why? Which cards give the desired information-L.C. cards or those from other libraries? Who is being interviewed -staff members or members of the public? On what subject is the person being interviewed (public) working? Is the request answered? Which section of the alphabet is being searched? Does the user know of the existence of the Book Catalog? If so, what is his attitude toward the Book Cata$\log$ in relation to the depository card cata$\log$ ?

Each person was interviewed each time he approached the depository catalog during the period of this study when the interviewer was on duty. The schedule previously prepared was followed with the information thus derived, recorded by checking in the proper space on a separate card for each interview held. If additional information seemed necessary, it was written on the card.

Those interrogated represented members of the staff of the university libraries and a cross section of its public. For purposes of analyses the staff members were divided into groups according to the departments in which they were employed as follows: (I) reference, (2) cataloging, (3) acquisition, (4) circủlation, (5) departmental. The first four groups were staff members of the main library. Group five included staff members from departmental libraries on the campus.

The public was divided for purposes of analyses into ( $\mathrm{I}$ ) undergraduate students $\mathrm{I}$, $2,3,4$; (2) graduate students: (a) master, (b) doctor; (3) faculty; (4) permit; (5) research worker. Other categories added later were (I) first-year school of library service students; (2) faculty from other schools; (3) librarians from off-campus libraries; (4) all other users who did not fall into the above groups.

The gathering of the data by interviews covered a span of six weeks divided into three two-week periods, chosen on the assumption that they were representative periods of the academic year. The periods fell approximately in the middle portion of the first semester, at the close of the first semester, and at the beginning of the second semester. The interviewing was so scheduled that every hour the library was open each day was covered sometime during the week. This averaged thirteen hours per week or approximately two hours per day of interviewing. At the end of the interview period of six weeks, the data were recorded and analyzed by types of users to show the number and percentage of requests answered, the sections of the catalog used, the type of card consulted, and the knowledge of the Book Catalog and attitudes toward it.

Several limitations should be pointed out. It is recognized that research in the fields of social science and the humanities especial$\mathrm{ly}$, and in science to a lesser degree, was affected by war. Less research as such was being done during this period, and, as a result, the probable use of the depository catalog might have been less than in normal times. However, while it is likely that the number of uses may have decreased, the types of use probably did not vary. It should also be pointed out that much current foreign material, which ordinarily might be represented in the depository catalog, had not been obtained by L.C. 


\section{Use by Staff}

A total of 625 interviews was recorded, 365 involving members of the staff and 260 the public. Of the 365 interviews conducted with the staff group, the greatest number, $22 \mathrm{I}$, or 60.6 per cent, were with members of the cataloging department; 72 , or 19.7 per cent, were with the reference staff; 48 , or I3.I per cent, were with members of the acquisition department; and 24, or 6.6 per cent, were with departmental librarians. Members of the circulation department staff did not use the depository catalog during the course of this study.

The cataloging department made the most varied use of the depository catalog among staff members. Sixteen different uses by this department were recorded. The chief ones were locating and withdrawing cards for aid in cataloging and in ordering L.C. cards. During the course of this study, it was found that the catalog was used by members of the cataloging department 112 times for the purpose of withdrawing cards and twenty-four times for the purpose of ordering L.C. cards. Verification of author or title to establish an entry ranked second in order as a reason for using the depository catalog by the cataloging staff. It was referred to eighty-three times, or $3 \mathrm{I} .3 \mathrm{per}$ cent of the total use of the catalog by this department, for the purpose of verification. Establishing corporate entries, searching for subject headings and classification numbers, editions, serial changes, cross references, added entries, analytics, date of volume, illustrator, series, and translator were other reasons given by this group for consulting the depository cata$\log$.

The location of the depository catalog in the reference room and the fact that the catalog is an acknowledged reference tool would lead one to believe that many varied uses could be made of the catalog by the reference staff. However, during the course of this study, it was found that this department used the depository catalog chiefly for verification of authors and titles and for interlibrary loan. Fifty-one requests, or 70.7 per cent of the total number of uses made of the depository catalog by the reference department during this study, were for verification. The catalog was used fourteen times for verification and location in connection with interlibrary loan service.

As might be expected, the chief use of the depository catalog by the acquisition department is that of searching or verifying items requested for purchase. Cards in the depository catalog were used forty-one times by searchers from the acquisition department who were either checking or verifying entries. This is 85.4 per cent of the total number of uses made of the catalog by members of the acquisition department. The only other use of the depository catalog by acquisition department staff members was for Library of Congress card numbers to be used in ordering sets of the printed cards. These cards are for books which are in the "in-process file." They are usually collections of books which will not be held but will be sent through at once to be processed and shelved. ${ }^{11}$ The depository catalog was used seven times during this study by the acquisition department for the purpose of ordering L.C. cards.

Although there are over thirty departmental libraries and reading rooms in the university library system, members of the staffs from only ten of them were interviewed during this study. The libraries which used the depository catalog were as follows: journalism, social'science, Plimpton, special collections, philosophy, modern languages, lending service, teachers college, and law. The depository catalog was used

$\mathbf{1 1}$ This procedure was followed for a short time only, but after this study was made it was abandoned. 
twenty-eight times for six different purposes by librarians employed in the above-mentioned departmental libraries.

The two greatest uses of the depository catalog by the departmental library staff members was to find Library of Congress card numbers for ordering cards and to verify author and title. Searching for items to be purchased was another use made of the depository catalog. In this study it was found that the depository catalog was used eight times for locating L.C. card numbers and thirteen times for verification. The edition of a book, the series to which a book belongs, and serial changes were other uses made of the depository catalog by the departmental libraries.

\section{Use by Public}

Of the 260 interviews conducted with the public over the three periods, the greatest number, 163 , or 62.7 per cent, were with students enrolled in Columbia University and its colleges. These included undergraduates, first-year school of library service students, and graduate students - candidates for both master's and doctoral degrees. Use of the depository catalog by faculty members of Columbia and other schools was recorded thirty-four times. Columbia faculty members consulted the catalog twenty-eight times, and off-campus faculty members six times. Librarians from off-campus libraries used the catalog twenty-one times. Most of these librarians were from within the city, but some were from adjoining communities. Research workers were interviewed nineteen times. Permit holders were recorded thirteen times; these included graduates of the university as well as those with special permits issued by the director's office. Those who did not fall into any . of the above-mentioned categories were placed in one group and called "all others." These included members of the armed forces, students from other schools, and wives and secretaries of faculty members. The catalog was consulted ten times by this group.

Graduate students made the most varied use of the depository catalog among members of the public. The chief reasons for consulting the catalog involved verification of entries eighteen times, or 39.1 per cent, for term papers, theses, and recommended reading; compilation of bibliographies seven times, or 15.2 per cent and 29.2 per cent, by master's and doctoral students respectively; location of books for interlibrary loan eleven times for master's students and twelve times for doctoral candidates. Firstyear school of library service students used the depository catalog chiefly for the purpose of establishing entries for authority files and for verification of correct entries. These were for assignments given in a cataloging class.

Undergraduate students used the depository catalog ten times for the compilation of bibliographies preparatory to writing term papers for English classes. Although a total of twenty-three undergraduate students were interviewed, thirteen of this group admitted, during the course of the interview, that they had confused the $\mathrm{Li}$ brary of Congress catalog with the Columbia catalog.

Among the largest groups of public users were faculty members of the university and of other schools within the city. Thirty-four of the public interviews were with members of this group. Twenty-eight were with members of the faculty of Columbia, and six were with those associated with other educational institutions. The chief uses of the catalog by Columbia faculty were for verification of correct entries and checking to see what was available. Off-campus faculty used the catalog chiefly for location of books wanted for interlibrary loan. 
Permit holders were interested mainly in whether such books as they desired were in existence. Off-campus librarians searched for L.C. card numbers for the purpose of ordering L.C. cards. Research workers were using the catalog to check bibliographies. The "all other" group consulted the catalog to see what was available on a particular subject, for L.C. card numbers for a private library, a translation of a Spanish book, the making of a bibliography for an Italian publication, and the location of a certain edition.

Users of the catalog were interrogated as to the subject for which they were seeking information. The persons interviewed were working on diversified subjects, with the exception of school of library service students. This group was working on a single subject-cataloging. The principal subjects recorded were history, English literature, and Spanish.

Before each interview was finished the user of the catalog was asked if he knew of the publication of the Book Catalog and his attitude toward it. As was to be expected, all staff members knew of the existence of the printed catalog in book form. Among the public 115 did not know of the publication; 145 , or 55.7 per cent, were aware of the set, but many had not used the volumes. The majority of both groups stated that they preferred the cards to the Book Catalog, giving as the chief reason that "the print of the Book Catalog is too small and too hard to read."
Confusing the depository catalog with the Columbia card catalog was an unforeseen variable brought to light by this study. Of the public users, 12.3 per cent were confused in the two catalogs although both the Columbia catalog and the Library of Congress catalog are plainly marked.

\section{Summary}

Data gathered in the study of the use of the depository card catalog suggest that there should be serious doubt as to need for maintaining the card depository in the library studied now that the Book Catalog is available for practically all normal uses made of L.C. entries. The important exception is the use of L.C. cards in the cataloging process. Libraries, of course, could use the cut L.C. proofsheet cards for this purpose and probably at less expense.

The fact that the Book Catalog must be kept up-to-date by a card file and published supplements is a disadvantage. How serious this will be will depend on the arrangements made for keeping the Book Catalog up-to-date. ${ }^{12}$ Searching in several places will remain as a disadvantage.

The Book Catalog might have wider usage if it were called to the attention of those persons outside the library staff who would have the most need for such a tool. These include graduate students and faculty members especially.

\footnotetext{
12 Since this was written the Library of Congress has announced plans for the publishing of monthly, quarterly, and annual cumulations of L.C. entries in book form.
} 